2. Lewczuk J, Piszko P, Jagas J, et al. Prognostic factors in medically treated patients with chronic pulmonary embolism. Chest. 2001; 119:818-23.

3. Archibald CJ, Auger WR, Fedullo PF, et al. Long-term outcome after pulmonary thromboendarterectomy. Am J Respir Crit Care Med. 1999;160:523-8.

4. Jamieson SW, Kapelanski DP. Pulmonary endarterectomy. Curr Prob Surg. 2000;37: 165-252.

doi:10.1016/S0022-5223(03)00820-1

\section{Tuberculous aneurysm of the aortic arch}

\section{To the Editor:}

We read with interest the recent article of Hatem and colleagues. ${ }^{1}$ We report here an additional surgical case of tuberculous aneurysm of the thoracic aorta with some resemblance to their case report.

A 52-year-old man was admitted to the hospital. He was previously healthy and reported a 6-week history of fever, malaise, and weight loss. On admission, results of cardiothoracic examination were normal, and all upper and lower extremity pulses were palpable. The chest radiograph showed a diffuse micronodular pattern in both lung fields. Bronchoscopic lung examination and biopsy revealed granulomatous pneumonitis with the presence of Langhans cells. The Ziehl-Neelsen test result was positive. The diagnosis was tuberculosis, and subsequently treatment with antituberculous agents was administered. Results of blood and urine analyses were normal. Investigation for HIV infection had negative results. Computed tomographic scan (Figure 1, A) and digital aortography (Figure 1, $B$ ) disclosed a localized aneurysm in the aortic arch. A diagnosis of mycotic aneurysm of the thoracic aorta was reached. The patient underwent operation on May 3, 1994. A left thoracotomy through the fourth intercostal space was accomplished, and an inflammatory aneu-

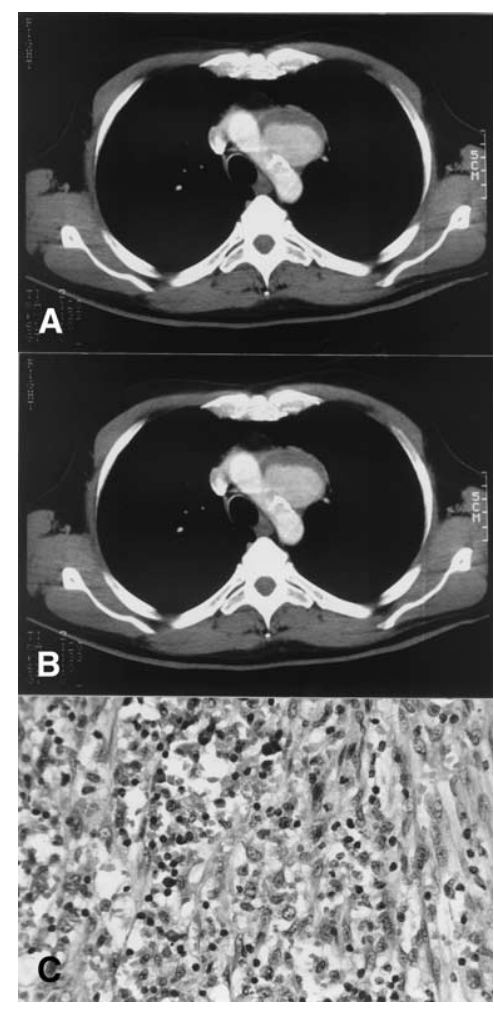

Figure 1. A, CT scan shows aneurysm in aortic arch. B, Digital aortography demonstrates saccular aneurysm in aortic arch. Remainder of thoracic aorta is angiographically normal. C, Arterial wall of aortic arch and aneurysm showing inflammatory signs with lymphocytes, histiocytes, plasmatic cells, and giant cells of Langhans type (hematoxylin and eosin, original magnification $\times 200$ ).

rysm of the distal aortic arch was exposed. The left upper lobe of the lung was involved in the process and was dissected off the aneurysm. The left subclavian artery, distal descending thoracic aorta, and part of the aneurysm were isolated. During dissection of the proximal aortic arch, the aneurysm ruptured, with massive cataclysmic hemorrhage. Despite clamping of the aortic arch, rapid transfusion, and other maneuvers, the patient exsanguinated and died in the operating room.

The upper left lung, aortic arch, and mediastinal lymph nodes were sent for pathologic study. The histopathologic examination of the lung and nodes was consistent with tuberculosis, as was that of the walls of the aorta and aneurysm, which showed an inflammatory pattern with lymphocytes, histiocytes, plasmatic cells, and giant cells of Langhans (Figure 1,C).

We agree with Hatem and colleagues ${ }^{1}$ regarding the extreme rarity of tuberculous aneurysm of the thoracic aorta. In 1996 Izekawa coworkers ${ }^{2}$ published a case report and in a review collected 32 additional surgical cases. Since then, a few more cases have been reported. ${ }^{3,4} \mathrm{We}$ believe that our case reported here may be useful and of interest to complete the scarce bibliographic list of this uncommon entity.

Cipriano Abad, MD

Department of CardioVascular Surgery Hospital Universitario de GC Dr Negrin Las Palmas de Gran Canaria, Spain Paloma Santamaria, MD Department of Pathology

Hospital Universitario de GC Dr Negrin Las Palmas de Gran Canaria, Spain

\section{References}

1. Hatem CM, Kantis GA, Christoforou D, Gold JP, Plestis KA. Tuberculous aneurysm of the descending thoracic aorta. $J$ Thorac Cardiovasc Surg. 2002;123:373-4.

2. Ikerzawa T, Iwatsuka Y, Naiki K, Asano M, Ikeda S, Kimura A. Tuberculous pseudoaneurysm of the descending thoracic aorta: a case report and literature review of surgically treated patients. J Vasc Surg. 1996;24:693-7.

3. Long R, Guzman R, Greenberg H, Safneck J, Harshfield E. Tuberculous mycotic aneurysm of the aorta: review of published medical and surgical experience. Chest. 1999;115:522-31.

4. Strnad BT, McGraw JK, Heatwole EV, Clark $\mathrm{P}$. Tuberculous aneurysm of the aorta presenting with uncontrolled hypertension. $J$ Vasc Interv Radiol. 2001;12:521-3. doi:10.1016/S0022-5223(03)00789-X 